УДК 371.3

DOI: $10.15330 /$ esu. $17.325-332$
Богдан Дрінь,

кандидат педагогічних наук, доцент, ДВНЗ "Прикарпатський національний університет імені Василя Стефаника" (м. Івано-Франківськ, Україна)

Bohdan Drin,

Candidate of pedagogical sciences (PhD),

Associate Professor, Vasyl Stefanyk Precarpathian National university (Ivano-Frankivsk, Ukraine) dbog1950@gmail.com

\author{
Артур Поліщук, \\ магістрант, ДВНЗ “Прикарпатський національний \\ університет імені Василя Стефаника" \\ (м. Івано-Франківськ, Україна) \\ Artur Polishchuk, \\ Graduate student, Vasyl Stefanyk Precarpathian \\ National University (Ivano-Frankivsk, Ukraine) \\ artur_polishchuk@comp-sc.if.ua
}

\title{
МУЛЬТИМЕДІЙНІ ЗАСОБИ НАВЧАННЯ: МЕТОДИЧНИЙ АСПЕКТ РОЗРОБКИ
}

\section{MULTIMEDIA LEARNING TOOLS: A METHODOLOGICAL ASPECT OF WORKING}

Матеріали статі присвячені проблемі впроваджения мультимедійних засобів навчання (МЗН) в освітній прочес закладів загальної середньої освіти (ЗЗСО). Проведено моніторинг впровадження та використання МЗН в ЗЗСО в иколах сільській місиевості. Проаналізовано їх вплив на якість освітнього прочесу, хмариі технології для розробки МЗН, їх переваги та недоліки, а також основні методики розробки МЗН. Розроблено рекомендований перелік хмарних сервісів для створения МЗН, відповідно до вимог та реалій освітнього прочесу в З3СО, а також рекомендації иродо використання МЗН на різних етапах уроку в залежності від дидактичної мети. Визначено необхідність покращения інформачійної компетентності педагогів та иляхи вирімення даної проблеми.

Ключові слова: мультимедіа; мультимедійні засоби навчання; хмарні технологіӥ; сервіси Google; GoogleClassroom.

The article is devoted to the problem of the introduction of multimedia learning tools (MLT) in the educational process of institutions of general secondary education (IGSE). The article determines the levels of mastery and utilization of MLT in the educational process in rural areas, through an anonymous survey of teachers. The results of this survey suggest that educators generally do not master methods for creating MLT, and instead prefer multimedia presentations. Thus they ignore other technologies and software. The main cause of these results is the poor information competence of teachers.

The article continues analyzing the software tools used for the creation of MLT. After considering different technologies and the dynamics of the development of cloud technologies, the researchers came to the conclusion that cloud technologies can become an effective tool in the hands of Ukrainian educators. The advantages of using such cloud technologies are still being revealed.

To provide guidance to educators on how to choose a service to create a MLT, an analysis of online services was conducted and a recommended list was developed. When choosing a service, attention was paid to the following criteria: free of charge, ease of use, intuitive interface and localization in Ukrainian.

The article states that the development of the MLT is an integral part of the teacher's preparation for the lesson, which is divided into two main stages: preliminary and direct 
preparation. The direct preparation phase requires a thorough understanding of each structural element of the lesson. The structural elements of the lesson include: checking and reviewing homework, updating and correcting basic knowledge, identifying topics, goals and lesson objectives, motivation of students' learning activities, perception and initial awareness of new learning material, generalization and systematization of knowledge, the use of knowledge in the standard and changed conditions, testing students' knowledge of factual material and basic concepts, ability to uncover external and internal connections in objects and phenomena, testing students' ability to apply knowledge in standard and non-standard conditions and summarizing the lesson.

These elements can interact in different combinations, at different levels, defining the overall structure of the lesson. This stricture which depends primarily on the didactic goal, the content of the educational material and the learning abilities of the students. In the process of preparation for the lesson, the teacher's task is to determine the expediency of using the MLT and to choose their type and method of program implementation.

The article also provides recommendations on the use, different types of MLT and the software tools for creating them for each structural element of the lesson according to the selected type.

Key words: multimedia; multimedia learning tools; cloud technologies; Google services; Google Classroom.

Вступ. Постановка проблеми. Сучасний освітній процес неможливий без використання мультимедіа-технологій як інструменту для вдосконалення оптимізації навчального процесу.

Мультимедійні засоби навчання (МЗН) є невід'ємним компонентом практично будь-якої сучасної методичної системи, оскільки вони є інструментом візуалізації й оцінювання процесу навчання, пошуку, отримання та опрацювання даних різноманітного походження. Використання мультимедіа сприяє індивідуалізації навчання, створенню самостійності та пошукового характеру пізнавальної діяльності, стимулює до самонавчання, посилює міжпредметні зв'язки у навчанні, підвищує гнучкість та мобільність навчального процесу. Також необхідно зазначити, що дидактичні можливості МЗН зростають за мірою розвитку їх техніко-технологічного та програмно-методичного рівня.

В процесі розробки та створення МЗН багато викладачів та вчителів стикаються 3 проблемою вибору виду МЗН та його реалізації за допомогою того чи іншого програмного сервісу. Також слід відмітити низький рівень інформаційної компетентності педагогів особливо в закладах освіти в сільській місцевості, що $\epsilon$ основною перешкодою ефективного використання МЗН в освітньому процесі.

Аналіз досліджень 3 теми. Значна кількість наукових праць присвячена питанню використання мультимедіа в освітньому процесі. Зокрема американські дослідники Л. Скіббе, С. Хейфмейстер, А. Чеснат називають цифрові технології “Еволюцією в прогресі", відзначаючи, що мультимедіа є змішаною технологічною прогресією, а не просто комбінацією апаратних і програмних компонентів. Вони трактують цифрові технології як "комбінацію платформ, інструментів комунікації, людей і впливу на культуру" [1, с. 270].

Значний внесок у теорію сприйняття і засвоєння різних видів інформації, зокрема, вплив на органи чуття аудіовізуальної інформації внесли В. Беспалько, Л. Виготський, А. Леонтьєв, Н. Тализіна, І. Якиманська та інші. 
Питання розробки засобів мультимедійної візуалізації розглядаються в роботах М. Бєляєва, Л. Зайнутдинової, Р. Краснової, К. Кречетнікова, А. Солового, Л. Чуксиної [2].

Жук Ю.О. виділяє наступні дидактичні особливості, що надають перевагу мультимедійним засобам в порівнянні $з$ традиційними [3, с. 33]:

- інформаційна насиченість; унаочнення представленої інформації істотно нового рівня;

- можливість поєднання логічного та образного способів опанування інформації;

- можливість представлення змісту на трьох рівнях: спостереження, теоретичному і практичному, що дозволяє інтегрувати абстрактність теоретичного 3 конкретикою і наочністю практичного знання;

- реалізація особистісного підходу до навчання: можливість підлаштовуватись під індивідуальний стиль того, хто навчається;

- можливість здійснення інтерактивної взаємодії, спілкування в інформаційноосвітньому просторі;

- розширення засобів для реалізації вчителем творчих підходів до методики викладання предмету.

Метою даного дослідження є розробка методики створення МЗН, в залежності від виду дидактичної мети уроку та його складових, а також розробка методичних рекомендацій для педагогів щодо вибору програмних засобів для реалізації даної методики.

Методи дослідження: у процесі дослідження використовувалися методи теоретико-критичного аналізу психолого-педагогічної та методичної літератури 3 теми дослідження, порівняння, систематизація, узагальнення здобутої інформації, а також методи масового збору емпіричного матеріалу.

Виклад основного матеріалу. На шляху розвитку інформаційного суспільства якісна освіта стає одним 3 головних чинників успіху, а педагог є одночасно i об’єктом, і провідником позитивних змін [4]. Умови, в яких працює сучасний педагог вимагають від нього все більшого залучення в освітній процес МЗН, які частиною IКТ. Вони включають в себе дуже великий спектр засобів.

3 метою визначення рівня володіння та використання МЗН в освітньому процесі, в дослідженні було проведено анонімне опитування педагогів в сільські місцевості. В опитуванні взяли участь 187 педагогічних працівників 33СО Делятинської ОТГ, 3242 що складає 77,3\% від загальної кількості педагогічних працівників. На запитання "Чи використовуєте на своїх уроках мультимедійні засоби навчання?" 92,5\% відсотки опитаних відповіли ствердно, проте 3 відповіді на питання "Як часто ви використовуєте на своїх заняттях мультимедійні засоби навчання" тільки $38 \%$ опитаних відповіли, що або зовсім не використовують їх, або дуже рідко (при проведенні відкритих уроків тощо). Такий самий показник (38\%) тих педагогів, які не вміють самостійно створювати МЗН. При цьому спостерігається чітка залежність за віком педагогів, а саме: чим молодші педагоги тим більший відсоток тих, що володіють навичками створення МЗН. За результатами даного опитування можна зробити висновок, що педагоги, в основному, не володіють методикою створення МЗН, та надають перевагу мультимедійним презентаціям, ігноруючи інші технології та програмні засобами. Причиною цього $є$ низька інформаційна компетентність педагогів.

Наступним етапом дослідження був аналіз програмних засобів для створення МЗН. Розглянувши різні технології, та врахувавши динаміку розвитку хмарних 
технологій, дійшли висновку, що саме вони можуть стати ефективним інструментом в руках українських педагогів. До переваг хмарних технологій можна віднести:

- економію коштів (вони не вимагають великих обчислювальних потужностей ПК, велика кількість хмарний сервісів $є$ безкоштовними, і можуть задовольнити потребу користувачів у всіх видах обчислень);

- відсутність потреби у кваліфікованих працівниках для установки та підтримання ПЗ;

- доступ до інформації з будь якого місця, де $є$ підключення до Інтернету, та 3 будь якого пристрою (ПК, ноутбук, смартфон, планшет);

- певну безпеку даних;

- екологічність.

Для надання рекомендацій педагогам, щодо вибору сервісу для створення МЗН, був здійснений аналіз онлайн сервісів та розроблений їх рекомендований орієнтовний перелік, який представлений в таблиці 1. При виборі сервісу увага зверталася на такі критерії: безкоштовність, простота у використанні, інтуїтивно зрозумілий інтерфейс та локалізація українською мовою.

Таблиця 1.

Орієнтовний перелік хмарних засобів для створення МЗН

\begin{tabular}{|c|c|c|c|}
\hline \multirow{2}{*}{$\begin{array}{l}\text { № } \\
\text { 3/ח }\end{array}$} & \multirow{2}{*}{$\begin{array}{c}\text { Категорія } \\
\text { сервісів }\end{array}$} & \multicolumn{2}{|r|}{ Перелік сервісів } \\
\hline & & для початківців & для досвідчених користувачів \\
\hline 1 & $\begin{array}{c}\text { офісні технологіі, } \\
\text { документ - } \\
\text { сервіси }\end{array}$ & $\begin{array}{l}\text { GoogleDocs, } \\
\text { Microsoft Office } \\
\text { Online, }\end{array}$ & Zoho Writer, DropBoxPaper \\
\hline 2 & $\begin{array}{l}\text { Графічні - } \\
\text { редактори }\end{array}$ & Pixlr & Fotor, Befunky \\
\hline 3 & відео - редактори & $\begin{array}{l}\text { OnlineVideoCutter, } \\
\text { YouTube Творча } \\
\text { студія }\end{array}$ & ClipChamp, WeVideo \\
\hline 4 & аудіо-редактори & OnlineAudioCutter & $\begin{array}{l}\text { ApowersoftFreeOnlineAudioEditor, } \\
\text { TwistedWafe }\end{array}$ \\
\hline 5 & $\begin{array}{c}\text { сервіси для } \\
\text { створення } \\
\text { мультимедійних } \\
\text { презентацій } \\
\text { (слайд-шоу, } \\
\text { публікацій, } \\
\text { постерів, } \\
\text { інфографік) }\end{array}$ & $\begin{array}{l}\text { GoogleSlides, } \\
\text { Microsoft PowerPoint } \\
\text { Online }\end{array}$ & Prezi, ZohoShow \\
\hline 6 & $\begin{array}{c}\text { редактори тестів } \\
\text { та } \\
\text { опитувальників }\end{array}$ & GoogleForms & $\begin{array}{l}\text { ClassMarker, ProProfs, } \\
\text { EasyTestMaker }\end{array}$ \\
\hline 7 & віртуальні дошки & $\begin{array}{l}\text { Padlet (з автоматич- } \\
\text { ним перекладом } \\
\text { українською у } \\
\text { браузері), } \\
\text { GoogleKeep }\end{array}$ & Popplet, Rizzoma, Glogster \\
\hline
\end{tabular}




\begin{tabular}{|c|c|c|c|}
\hline 8 & $\begin{array}{c}\text { сервіси для } \\
\text { створення } \\
\text { інтелект - карт } \\
\end{array}$ & $\begin{array}{l}\text { iMindMap (з автома- } \\
\text { тичним перекладом } \\
\text { українською у } \\
\text { браузері) }\end{array}$ & $\begin{array}{l}\text { XMind, Bubbl.us, MindMeister, } \\
\text { MindMup }\end{array}$ \\
\hline 9 & $\begin{array}{c}\text { хостинги і } \\
\text { конструктори } \\
\text { сайтів та блогів }\end{array}$ & GoogleSites, uCoz & Wix, uKit, Jimbdo \\
\hline 10 & $\begin{array}{c}\text { сервіси для } \\
\text { організації } \\
\text { роботи з групами }\end{array}$ & $\begin{array}{l}\text { Classroom, Microsoft } \\
\text { Teams, GoogleDrive, } \\
\text { OneDrive }\end{array}$ & Moodle, DropBox \\
\hline 11 & $\begin{array}{c}\text { системи } \\
\text { спілкування в } \\
\text { реальному часі }\end{array}$ & $\begin{array}{l}\text { Skype, } \\
\text { GoogleHangouts, } \\
\text { Facebookmessenger, } \\
\text { Telegram, Viber }\end{array}$ & \\
\hline 12 & $\begin{array}{c}\text { сервіси для ство- } \\
\text { рення дидактич- } \\
\text { них матеріалів: } \\
\text { кросвордів, } \\
\text { пазлів, QR-кодів, } \\
\text { доповненої (AR) } \\
\text { реальності, } \\
\text { вікторин тощо }\end{array}$ & $\begin{array}{l}\text { OnlineTestPad, } \\
\text { learningapps.org, } \\
\text { Futurio }\end{array}$ & $\begin{array}{l}\text { Фабрика кросвордов, } \\
\text { jigsawplanet.com, pazlyonline.com, } \\
\text { quivervision.com }\end{array}$ \\
\hline
\end{tabular}

Розробка МЗН є складовою частиною підготовки вчителя до уроку (уроків), яка поділяється на два основні етапи [5]:

перший етап - попередня підготовка, яка включає вивчення навчальної програми, іiі пояснювальної записки, змісту програми, усвідомлення мети і завдань навчальної дисципліни, а також мети і завдань кожної теми;

другий етап - безпосередня підготовка.

Безпосередня підготовка вимагає глибокого осмислення кожного структурного елемента уроку. До структурних елементів уроку можна віднести: перевірку домашнього завдання, актуалізацію і корекцію опорних знань, повідомлення теми, мети, завдань уроку, мотивація навчальної діяльності учнів, сприймання і первинне усвідомлення нового навчального матеріалу, узагальнення і систематизація знань, застосування знань у стандартних i змінених умовах, перевірка знання учнями фактичного матеріалу й основних понять, уміння розкривати зовнішні та внутрішні зв'язки в предметах i явищах, перевірка вмінь застосування учнями знань у стандартних та нестандартних умовах, підбиття підсумків уроку.

Ці елементи можуть взаємодіяти в різних комбінаціях, на різних рівнях, визначаючи загальну структуру уроку, що залежить насамперед від дидактичної мети, змісту навчального матеріалу, навчальних можливостей учнів. В процесі підготовки до уроку завдання вчителя визначитись із доцільністю використання МЗН, вибрати його вид та спосіб програмної реалізації.

В таблиці 2 наведені рекомендації, щодо використання, різних видів МЗН, програмних засобів для їх створення для кожного структурного елементу уроку відповідно до обраного типу. 
Таблиця 2.

Використання мультимедійних засобів навчання при розробці різних типів уроків

\begin{tabular}{|c|c|c|c|c|c|c|c|}
\hline $\begin{array}{l}\text { Макрострук } \\
\text { турний } \\
\text { етап уроку }\end{array}$ & Мультимедійні засоби навчання & 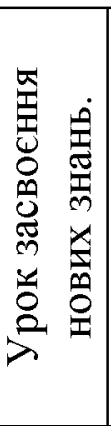 & 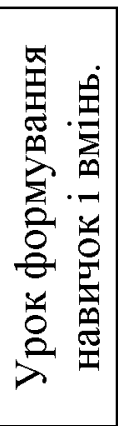 & 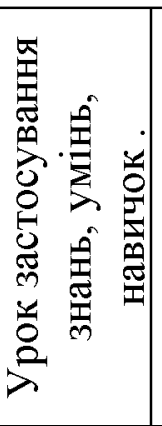 & 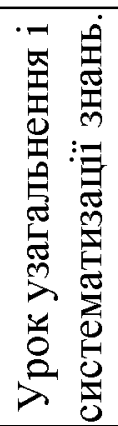 & 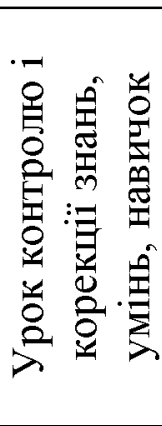 & \\
\hline 1 & 2 & 3 & 4 & 5 & 6 & 7 & 8 \\
\hline $\begin{array}{c}\text { перевірка } \\
\text { домашнього } \\
\text { завдання; }\end{array}$ & \begin{tabular}{|l} 
засоби організації роботи 3 \\
$\begin{array}{l}\text { групами ( GoogleClassroom, } \\
\text { сервіси GoogleDrive) }\end{array}$
\end{tabular} & + & + & + & + & & + \\
\hline $\begin{array}{l}\text { актуалізація } \\
\text { і корекція } \\
\text { опорних } \\
\text { знань; }\end{array}$ & 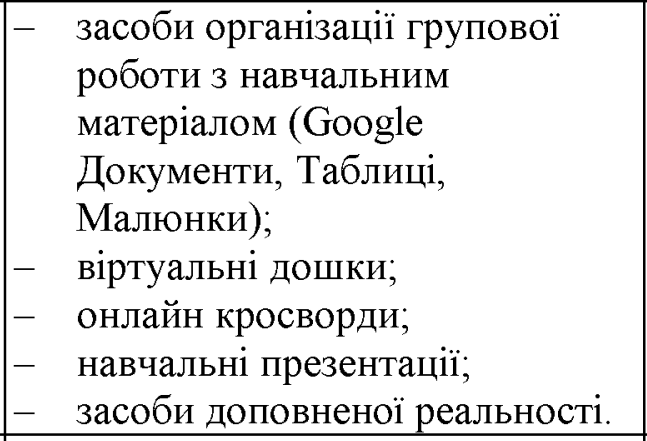 & + & + & + & + & & + \\
\hline \begin{tabular}{|c} 
повідомленн \\
я теми, мети, \\
завдань \\
уроку; \\
\end{tabular} & $\begin{array}{ll}- & \text { навчальні презентації; } \\
- & \text { навчальне відео. }\end{array}$ & + & + & + & + & + & + \\
\hline $\begin{array}{c}\text { мотивація } \\
\text { навчальної } \\
\text { діяльності } \\
\text { учнів } \\
\end{array}$ & $\begin{array}{l}\text { мотиваційні навчальні } \\
-\quad \text { відео; } \\
-\quad \text { аудіо; } \\
-\quad \text { зображення. } \\
\end{array}$ & + & + & + & + & + & + \\
\hline $\begin{array}{c}\text { сприймання } \\
\text { і первинне } \\
\text { усвідомленн } \\
\text { я нового } \\
\text { навчального } \\
\text { матеріалу }\end{array}$ & $\begin{array}{ll}- & \text { мультимедійні презентації; } \\
- & \text { навчальні відео; } \\
- & \text { навчальне аудіо; } \\
- & \text { доповнена та віртуальна } \\
& \text { реальності }\end{array}$ & + & & & & & + \\
\hline $\begin{array}{l}\text { Узагальнен- } \\
\text { ня і } \\
\text { систематиза } \\
\text { ція знань та } \\
\text { вмінь; }\end{array}$ & $\begin{aligned}- & \text { сервіси GoogleDrive, Microsoft } \\
& \text { OneDrive; } \\
- & \text { сервіси для створення } \\
& \text { навчальних вправ } \\
& \text { (LearningApps, OnlineTestPad } \\
& \text { тощо); } \\
- & \text { віртуальні дошки; } \\
- & \text { інтелект-карти; } \\
- & \text { мультимедійні презентації. }\end{aligned}$ & + & & + & + & & + \\
\hline
\end{tabular}




\begin{tabular}{|c|c|c|c|c|c|c|c|}
\hline $\mid \begin{array}{c}\text { застосування } \\
\text { знань у } \\
\text { стандартних } \\
\text { і змінених } \\
\text { умовах; }\end{array}$ & 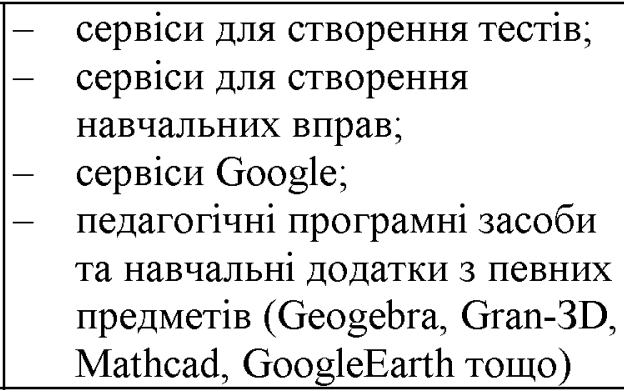 & & + & + & & & \\
\hline \begin{tabular}{|c|} 
перевірка \\
знання \\
учнями \\
фактичного \\
матеріалу й \\
основних \\
понять
\end{tabular} & $\begin{array}{ll}- & \text { сервіси для створення тестів; } \\
- & \text { засоби організації групової } \\
\text { роботи з навчальним } \\
\text { матеріалом (спільна робота } 3 \\
\text { Google Документами, } \\
\text { Таблицями, Малюнками); }\end{array}$ & & & & & + & + \\
\hline \begin{tabular}{|c|} 
перевірка \\
вмінь \\
застосування \\
учнями \\
знань у стан- \\
дартних та \\
нестандарт- \\
них умовах \\
\end{tabular} & 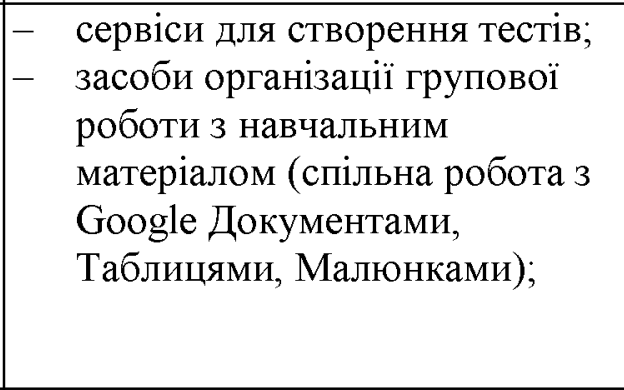 & & & & & + & \\
\hline $\begin{array}{l}\text { підбиття } \\
\text { підсумків } \\
\text { уроку; }\end{array}$ & $\begin{array}{l}-\quad \text { віртуальні дошки; } \\
\text { - } \text { форуми; } \\
\text { мультимедійні презентації. }\end{array}$ & + & + & + & + & + & + \\
\hline $\begin{array}{c}\text { Повідомлен- } \\
\text { ня } \\
\text { домашнього } \\
\text { завдання }\end{array}$ & $\begin{array}{ll}- & \text { мультимедійні презентації; } \\
- & \text { засоби організації зв’язку } \\
& \text { (чати, Viber, Skype тощо); } \\
- & \text { освітні сайти; } \\
\text { засоби роботи з групами } \\
\text { (GoogleClassroom). }\end{array}$ & + & + & + & + & + & + \\
\hline
\end{tabular}

Також треба зауважити, що протягом одного уроку можуть бути використані різні види МЗН. 3 метою їх об’єднання в одному програмному продукті, доцільно використовувати мультимедійні презентації, освітні авторські або тематичні сайти, а також засоби організації роботи 3 групами (Classroom) 3 використанням гіперпосилань. Якщо ж навчальний процес $є$ дистанційним, змішаним чи, наприклад, організований за технологією перевернутого класу то взагалі не обійтись без вебсайтів чи інших засобів роботи з групами користувачів онлайн.

Висновки. На підставі зробленого дослідження можна зробити висновок, що сучасні ІТ-технології, особливо хмарні технології, надають педагогам досить зручний, безкоштовний набір інструментів для створення та використання МЗН в своїй педагогічній діяльності, проте стан використання МЗН та рівень інформаційної компетентності педагогів потребує покращення, особливо в сільській місцевості.

Практична цінність даного дослідження полягає в тому, що використовуючи орієнтований перелік онлайн сервісів та методичні рекомендації для вчителів щодо вибору МЗН, можна підвищити інформаційну компетентність педагогів, заощадити час на вибір того чи іншого сервісу при розробці уроків, а також стимулювати вчителів до здійснення самоосвіти в даному напрямку. Також вони можуть бути вико- 
ристані під час організації курсів підвищення кваліфікації педагогічних працівників, розробці дистанційних та змішаних навчальних курсів для педагогів.

\section{Література}

1. Скиббе Л. Дж., Хэйфмейстер С., Чеснат А. М. Оптимизация мультимедиа ПК /Л. Дж. Скибб, С. Хэйфмейстер, А. М. Чеснат; пер. с англ. - К.: ДиаСофт Лтд, 1997. - 352 с.

2. Семеніхіна О., Юрченко А. Уміння візуалізувати навчальний матеріал засобами мультимедіа як фахова компетентність учителя // Науковий вісник Ужгородського національного університету: Серія "Педагогіка. Соціальна робота". - Ужгород: Видавництво УжНУ "Говерла". - Випуск 33. - 2014. - С. 176-179.

3. Мультимедійні системи як засоби інтерактивного навчання: посібник/ ав.: Жалдак М. I., Шут М. І., Жук Ю. О., Дементієвська Н. П., Пінчук О. П., Соколюк О. М., Соколов П. К. /За редакцією: Жука Ю. О. - К.: Педагогічна думка, 2012. - 112 с

4. Концепції розвитку педагогічної освіти України. [Електронний ресурс]. - Режим доступу: https://mon.gov.ua/ua/npa/pro-zatverdzhennya-koncepciyi-rozvitku-pedagogichnoyi-osviti

5. Гужанова Т.С. Урок як основна форма співпраці учителя i учнів у процесі навчання // Практикум 3 педагогіки: Навчальний посібник: Видання 2, доповнене, перероблене. /3а загальною редакцією Дубасенюк О.А., Іванченко А.В. - Житомир: Житомирський державний педуніверситет, 2002. - 482 с. - С. 166-180.

6. Нєнов О. Л. Програмні засоби мультимедійних систем: Навчальний посібник. Частина 1. Одеська національна академія харчових технологій, 2016. - $40 \mathrm{c}$.

7. Сліпухіна I.А., Поліхун Н.І., Чернецький I.C. Педагогіка XXI століття: формування цифрової дидактики. Збірник наукових праць "Педагогічні науки". 2018. Випуск LXXXIII, Tом 1. C. 231-237.

\section{References}

1. Skybbe L. Dzh., Kheifmeister S., Chesnat A. M. Optymyzatsyia multymedya PK /L. Dzh. Skybb, S. Kheifmeister, A. M. Chesnat; per. s anhl. - K.: DyaSoft Ltd, 1997. - 352 p.

2. Semenikhina O., Yurchenko A. Uminnia vizualizuvaty navchalnyi material zasobamy multymedia yak fakhova kompetentnist uchytelia // Naukovyi visnyk Uzhhorod National University : Seriia "Pedahohika. Sotsialna robota". - Uzhhorod: Vydavnytstvo UzhNU "Hoverla". - Vypusk 33. - 2014. - P. 176-179.

3. Multymediini systemy yak zasoby interaktyvnoho navchannia: posibnyk/ av.: Zhaldak M. I., Shut M. I., Zhuk Yu. O., Dementiievska N. P., Pinchuk O. P., Sokoliuk O. M., Sokolov P. K. /Za redaktsiieiu: Zhuka Yu. O. - K.: Pedahohichna dumka, 2012. - 112 p.

4. Kontseptsii rozvytku pedahohichnoi osvity Ukrainy. [Elektronnyi resurs]. - Rezhym dostupu: https://mon.gov.ua/ua/npa/pro-zatverdzhennya-koncepciyi-rozvitku-pedagogichnoyi-osviti

5. Huzhanova T.S. Urok yak osnovna forma spivpratsi uchytelia i uchniv u protsesi navchannia // Praktykum z pedahohiky: Navchalnyi posibnyk: Vydannia 2, dopovnene, pereroblene. /Za zahalnoiu redaktsiieiu Dubaseniuk O.A., Ivanchenko A.V. - Zhytomyr: : Zhytomyr Ivan Franko State University, 2002. -482 p. - P. 166-180.

6. Nienov O. L. Prohramni zasoby multymediinykh system: Navchalnyi posibnyk. Chastyna 1. Odessa National Academy of Food Technologies, 2016. - 40 p.

7. Slipukhina I.A., Polikhun N.I., Chernetskyi I.S. Pedahohika XXI stolittia: formuvannia tsyfrovoi dydaktyky. Zbirnyk naukovykh prats "Pedahohichni nauky". 2018. Vypusk LXXXIII, Tom 1. P. 231237.

Одержано статтю: 11.09 .2019

Прийнято до друку: 2.10.2019 